\title{
Estimating solar radiation according to semi empirical approach of PERRIN DE BRICHAMBAUT: application on several areas with different climate in Algeria
}

\author{
Mokhtar Ghodbane, Boussad Boumeddane \\ Faculty of Technology, University of Saad DAHLAB, Blida 1, CP 09000, Algeria
}

\begin{abstract}
The solar energy reaching a given surface is directly dependent on the orientation thereof and the position of the sun. To get maximum energy from the sun, it is necessary a good solar receiver orientation towards the solar radiation where the solar radiation is perpendicular to the solar collector, so the knowledge of the sun's position over time is a very important thing. The intensity calculate of solar radiation received by an inclined surface is the primary objective of this paper. The study is based on the true solar time, the geographic and astronomical data on-site study. Matlab was the simulation tool, where a program was developed to calculate the daily global solar radiation collected by any geographical site depending on the semi-empirical model of PERRIN DE BRICHAMBAUT. The some applications on different places in Algeria, like El-Oued, Biskra, Blida and Oran in the day of March 21, June 21, September 21 and December 21, and the results obtained were confirmed by comparing them with the previously results published by the researchers is of great competence in this field.
\end{abstract}

Keywords: solar energy, global solar radiation, inclined surface, simulation

$\begin{array}{ll}\text { Nomenclature } & \\ \mathrm{h} & \text { angular height of the sun }\left(^{\circ}\right) \\ \mathrm{j} & \text { Number of the day } \\ \mathrm{L} & \text { Longitude }\left(^{\circ}\right) \\ \mathrm{R}_{\mathrm{C}-\mathrm{h}} & \text { diffuse radiation from the sky intercepted by a horizontal surface }\left(\mathrm{W} / \mathrm{m}^{2}\right) \\ \mathrm{R}_{\mathrm{D}} & \text { Direct radiation }\left(\mathrm{W} / \mathrm{m}^{2}\right) \\ \mathrm{R}_{\mathrm{D}-\mathrm{C}}(\beta) & \text { diffuse radiation from the sky }\left(\mathrm{W} / \mathrm{m}^{2}\right) \\ \mathrm{R}_{\mathrm{D}-\mathrm{S}}(\beta) & \text { diffuse radiation from the ground picked up by a horizontal surface }\left(\mathrm{W} / \mathrm{m}^{2}\right) \\ \mathrm{R}_{\mathrm{f}-\text { inc }} & \text { inclination factor } \\ \mathrm{R}_{\mathrm{G}} & \text { global radiation }\left(\mathrm{W} / \mathrm{m}^{2}\right) \\ \mathrm{TVS} & \text { true solar time (hour) }\end{array}$

Greek letters

$\begin{array}{ll}\beta & \text { inclination angle of the inclined surface }\left(^{\circ}\right) \\ \alpha & \text { Azimuth }\left(^{\circ}\right) \\ \alpha_{\text {sol }} & \text { soil albedo } \\ \delta & \text { Declination }\left(^{\circ}\right) \\ \varphi & \text { Latitude }\left(^{\circ}\right) \\ \omega & \text { hour angle }\left(^{\circ}\right)\end{array}$




\section{INTRODUCTION}

The sun is a star; on the human plane this star is of paramount importance because without it life would not exist on earth. The characteristics of the sun are shown in the table below.

Table 1. Main characteristics of the Sun [1].

\begin{tabular}{lll}
\hline Characteristic & value & Unit \\
\hline Mass & $1,9891 \times 1030$ & $\mathrm{~kg}$ \\
Diameter & 1392684 & $\mathrm{~km}$ \\
Density & 1408 & $\mathrm{Kg} / \mathrm{m} 3$ \\
Surface & $6,0877 \times 1012$ & $\mathrm{Km}^{2}$ \\
Flux energetic & $3,826 \times 1026$ & $\mathrm{~W}$ \\
\hline
\end{tabular}

Solar energy is the oldest source of energy; it is at the origin of all the sources of energy such as: the wood, the coal, the natural gas, the oil and energy of the wind $[2,3]$. The performance calculation of the solar collectors requires the knowledge of the incident solar flux in term of the time, which in the function of the sun position in relation to the earth [4-11]. The Earth rotates on itself following an axis of rotation with a constant inclination in relation to the ecliptic plane, with which the equator makes an angle of $23.45^{\circ}$ [12]. It also runs in the plane of the ecliptic around the sun.

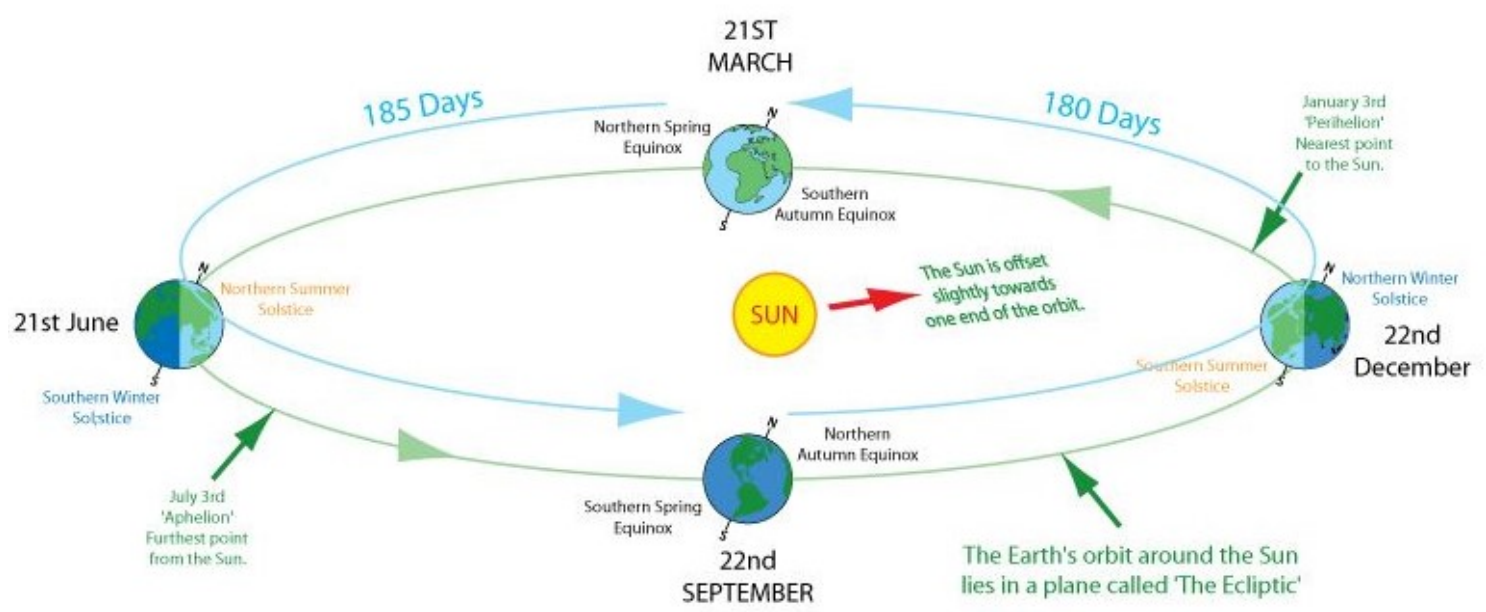

Fig.1. Earth movement around the sun.

The application of solar energy can be grouped into two main categories: high temperature applications (solar concentrators and solar collectors under vacuum), and low temperature applications (the generally flat plate collectors) [4].

In Algeria the climate is divided into three categories [4]:

- The Tell: characterized by a temperate Mediterranean climate, such as the site of Blida and Oran;

- The high plains: characterized by a continental climate;

- The Sahara: characterized by an arid and dry climate such as the site of El-Oued and Biskra. The notion of aridity does not concern only the desert areas but it affects all regions with scarce or erratic rainfall.

Table (2) shows the received sunshine annually in Algeria according to the climatic region.

Table 2. The received sunshine annually in Algeria [4].

\begin{tabular}{cccc}
\hline $\begin{array}{c}\text { Climate } \\
\text { category }\end{array}$ & The area ratio & hours of sunshine per year $(\mathrm{h} /$ year $)$ & $\begin{array}{c}\text { Average energy received } \\
\left(\mathrm{KWh} / \mathrm{m}^{2} / \text { year }\right)\end{array}$ \\
\hline The Tell & 4 & 2650 & 1700 \\
The high plains & 10 & 3000 & 1900 \\
The Sahara & 86 & 3500 & 2650 \\
\hline
\end{tabular}


In these pages, a computer program accomplished to calculate the incident solar radiation in the area on the surface of the earth. The MATLAB language was used as a device for programming. This incident solar radiation will be used as a data from other studies in the field of renewable energy, where the solar energy will be converted into heat energy or electricity. These transformations were according to the needs of use and the type of solar collector. The solar radiation was calculated in the following sites: El-Oued, Biskra, Blida and Oran. The reason for choosing these areas is the type of climate.

\section{GEOGRAPHICAL AND ASTRONOMICAL COORDINATES}

Any point of the terrestrial sphere can be spotted by two coordinates, these coordinates called terrestrial coordinates as follows:

- Latitude $(\varphi)$ : it is the angle between the earth place and the equator plane; it is counted positively towards the north,

- Longitude (L) of a location corresponding to the angle between the meridian planes passing through the area with a meridian plane chosen as origin.

Table 3. Terrestrial coordinates of the regions.

\begin{tabular}{lcll}
\hline \multicolumn{1}{c}{ Place } & Latitude $(\varphi)$ & Longitude $(\mathrm{L})$ & Altitude $(\mathrm{Z})$ \\
\hline El-Oued & $33^{\circ} 22^{\prime} 06^{\prime \prime} \mathrm{N}$ & $6^{\circ} 52^{\prime} 03^{\prime \prime} \mathrm{E}$ & Practically at the sea [13]. \\
Biskra & $34^{\circ} 51^{\prime} 00^{\prime \prime} \mathrm{N}$ & $5^{\circ} 44^{\prime} 00^{\prime \prime} \mathrm{E}$ & $87 \mathrm{~m}$ above the level of the sea [14]. \\
Blida & $36^{\circ} 29^{\prime} 00^{\prime \prime} \mathrm{N}$ & $2^{\circ} 50^{\prime} 00^{\prime \prime} \mathrm{E}$ & $260 \mathrm{~m} 260 \mathrm{~m}$ above the level of the sea [15]. \\
Oran & $35^{\circ} 42^{\prime} 10^{\prime \prime} \mathrm{N}$ & $0^{\circ} 38^{\prime} 57^{\prime \prime} \mathrm{W}$ & Min. 0 m - Max. 429.3 m above sea level [13]. \\
\hline
\end{tabular}

The angle between the terrestrial equator planes and the earth-sun direction is called the declination $\delta$. This angle varies throughout the year symmetrically of $-23^{\circ} 26^{\prime}$ 'to $23^{\circ} 26^{\prime}$ [14]. So declination $(\delta)$ is the point's latitude of the earth which are achieved by the midday sun (noon-solar), it is directly related to day (j) of the year as it turns out in the relationship (1) [16].

$$
\delta=23,45^{\circ} \sin \left[0,980^{\circ}(\mathrm{j}+284)\right]
$$

\subsection{Hourly coordinates}

The hour angle $(\omega)$ is the angle between the vertical plane of the place and the meridian plane passing through the center of the sun, it is given by:

$$
\omega=\frac{360}{24}+(\mathrm{TSV}-12)
$$

\subsection{Horizontal coordinates}

The position of a star in the space can be identified by its horizontal coordinate defined on the celestial sphere namely an angular height $(h)$ and an azimuth $(\alpha)$. So the position of the sun in a place, in a date and at any time depends on two angles:

Azimuth $(\alpha)$ is the angle between the projection of the sun direction on the ground and the south. It is measured from the South to the West positively zero at solar noon. The relation of the azimuth is:

$$
\sin \alpha=\frac{\cos \delta \sin \omega}{\cosh }
$$

Height of the sun (h) is the angle that the sun direction with its projection on the ground, it varies from $0^{\circ}$ to $90^{\circ}$ in the southern hemisphere (Nadir), vanishes at sunrise and sunset and is maximal in the south-solar.

$$
\sin \mathrm{h}=\cos \varphi \cos \delta \cos \omega+\sin \varphi \sin \delta
$$




\section{SOLAR RADIATION RECEIVED BY INCLINED SURFACE}

Solar energy is an inexhaustible source of energy and clean, which does not cause harmful emissions to our environment. It is propagated in the space on the form of photons. Therefore, it is available everywhere and cease renewable. The solar field is a set of data describing the evolution of the solar radiation available during a given period. Its evolution can be done using data of global solar irradiation.

Figure 2 illustrate the number of daily insolation hours on the last day of each month during the year, which the length of the daylight period for the last day of each month in the selected areas of study.

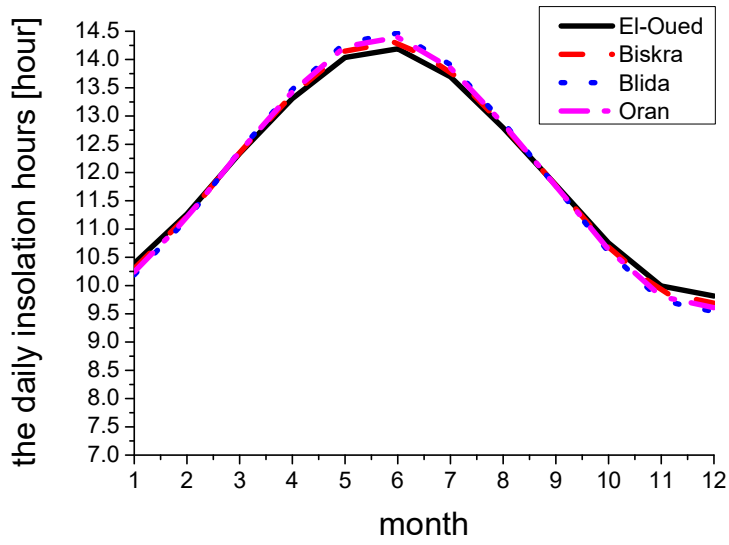

Fig.2. The number of daylight hours according of the last day of each month.

So in all sites, the daily insolation hours is varied for each month between 09 hours and 14.5 hours depending on the season of each month, that's why during the winter months, the amount received is less because of the low height of the sun. Roughly the number of hours of daily insolation in the four sites is important.

There is several models give a solar radiation depending on atmospheric and astronomical parameters. Generally, they expressed by semi empirical approaches; the most commonly known and used in practice is mainly include the PERRIN DE BRICHAMBAUT model and the LIU JORDAN model. This work will be based on the approach of PERRIN DE BRICHAMBAUT.

\subsection{The PERRIN DE BRICHAMBAUT model}

The global solar radiation $\left(\mathrm{R}_{\mathrm{G}}\right)$ arriving on a surface directed to the south with a slope $(\beta)$ consists of direct radiation and diffuse radiation $[2,3,17,18]$.

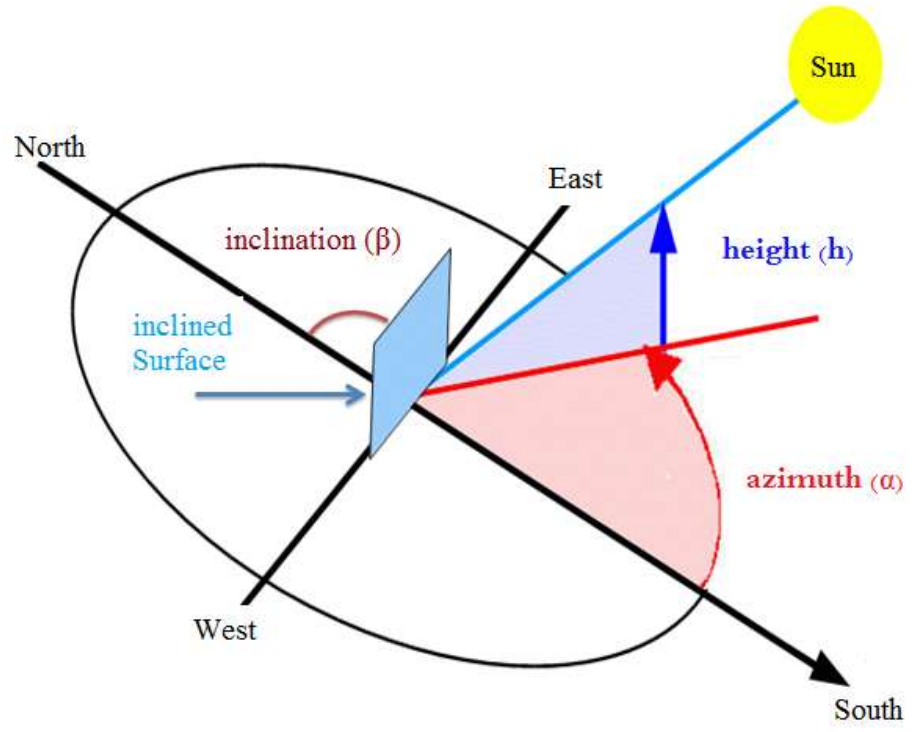

Fig.3. Characteristics of a flat plate collector directed to the south. 
It can be estimated the global solar radiation at any time and in any location from the Eq. (5).

$$
\mathrm{R}_{\mathrm{G}}=\mathrm{R}_{\mathrm{D}} \times \mathrm{R}_{\mathrm{f}-\mathrm{inc}}+\mathrm{R}_{\mathrm{D}-\mathrm{C}}(\beta)+\mathrm{R}_{\mathrm{D}-\mathrm{S}}(\beta)
$$

With $\left(\mathrm{R}_{\mathrm{D}}\right)$ is the direct radiation $\left(\mathrm{W} / \mathrm{m}^{2}\right)[3,19]$, generally the semi-empirical formulas as eq. 6 is used to calculate it.

$$
R_{D}=A \times \exp \left(\frac{-1}{B \times \sin (h+C)}\right)
$$

A, B and C are empirical constants that depend on the state of the Sky, in which these values are from table (4).

Table 4. The values of the constants $A, B$ and $C$ in terms of the nature of the Sky.

\begin{tabular}{cccc}
\hline Sky condition & A & B & C \\
\hline Clear Sky & 1210 & 6 & 1 \\
normal conditions of clear Sky & 1230 & 3.8 & 1.6 \\
Clear Sky polluted & 1260 & 2.3 & 3
\end{tabular}

$\mathrm{R}_{\mathrm{f}-\mathrm{inc}}$ is the inclination factor; it is given by the following relationship:

$$
\mathrm{R}_{\mathrm{f}-\mathrm{inc}}=\left(\frac{\cos (\varphi-\beta) \cos (\omega) \cos (\delta)+\sin (\varphi-\beta) \sin \delta}{\cos (\varphi) \cos (\omega) \cos (\delta)+\sin (\varphi) \sin (\delta)}\right)
$$

$D_{R-C}(\beta)$ is the scattered radiation which is received by a tilt surface with inclination angle $(\beta)$.

$$
\mathrm{R}_{\mathrm{D}-\mathrm{C}}(\beta)=\left(\frac{1+\cos (\beta)}{2}\right) \mathrm{R}_{\mathrm{C}-\mathrm{h}}
$$

$\mathrm{R}_{\mathrm{C}-\mathrm{h}}$ is the diffuse radiation [W.m- ${ }^{2}$ ], intercepted by a horizontal surface.

$$
\mathrm{R}_{\mathrm{C}-\mathrm{h}}=125 \times \mathrm{D} \times(\sinh )^{0,4}
$$

$\mathrm{D}$ is an empirical observation that depends on the state of the sky, whose values are expressed according to the following table:

Table 5. The value of the constant D depending on the nature of Sky.

\begin{tabular}{cc}
\hline Sky condition & D \\
\hline Clear Sky & $3 / 4$ \\
normal conditions of clear Sky & 1 \\
Clear Sky polluted & $4 / 3$
\end{tabular}

$\mathrm{D}_{\mathrm{R}-\mathrm{S}}(\beta)$ is diffuse radiation coming from the soil and is received by a horizontal surface [20]. 


$$
\mathrm{R}_{\mathrm{D}-\mathrm{S}}(\beta)=\alpha_{\text {sol }}\left(\frac{1-\cos (\beta)}{2}\right)\left(\mathrm{R}_{\mathrm{D}} \times \sin \mathrm{h}+\mathrm{R}_{\mathrm{C}-\mathrm{h}}\right)
$$

$\alpha_{\text {sol }}$ is a reflectivity or an albedo of the soil; it depends on the nature thereof. Some average values are summarized in Table (5).

Table 6. A few albedo values based on the nature of the soil [4, 21].

\begin{tabular}{cc}
\hline Type of Soil & average reflectivity (albedo) \\
\hline snowy Soil & 0.70 \\
Ground covered with dead leaves & 0.30 \\
green grass & 0.26 \\
Forest in autumn or golden fields & 0.26 \\
Pebbles white stones & 0.20 \\
dry grass & 0.20 \\
clay soil & 0.17 \\
Forest in winter (without snow coniferous trees) & 0.07 \\
Waterhole (high sunshine hours $>30^{\circ}$ ) & 0.07 \\
\hline
\end{tabular}

\section{RESULTATS AND DICUSSION}

To calculate the global solar radiation from sunrise to sunset, an algorithm was developed that can simulate solar radiation by the semi-empirical model PERRIN DE BRICHAMBAUT. The global radiation was calculated in clear sky conditions for the 21st day of the following month: March, June, September and December in the areas of El-Oued, Biskra, Blida and Oran. Figure 4 presents the calculation chart.

\section{The data:}

- the month and day;

- Type of Sky;

- Location;

- angle of inclination of the inclined surface (collector) ;

\section{The calculations:}

- Angle declination of the sun;

- $\quad$ incidence angle;

- $\quad$ height of the sun;

- Azimuth of the sun;

- Time of sunrise and sunset.

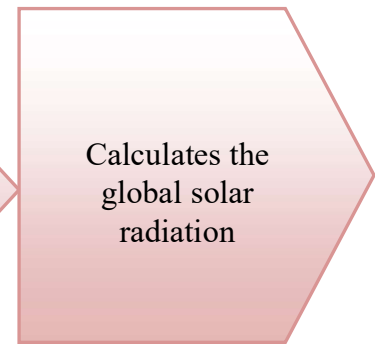

Fig.4. Simulation flow chart.

The change in global solar radiation particularly depends on the geographical coordinates of the location considered and the day number of the year. The results are simulated from a sunrise to a sunset, the collected radiation varies proportionally to the time of day, and the variation recorded due to the position of the sun during the day. So, the primary objective of this program is to calculate the amount of solar radiation to estimate the quantity of energy received by the solar collectors (especially the flat solar collectors). Just choose the day, month, type of sky the latitude of the location and angle of inclination. The results will give the global radiation values in graph form.

After inputting data of the site, the evolution allures of the global solar radiation were traced, these radiations are received by an inclined surface (or plane) with an inclination angle equal to the latitude of the selected site. The results of the four typical days "March 21, June 21, September 21 and December 21 (correspond to the solstices and equinoxes)" are shown in the figures $5 \mathrm{a}-5 \mathrm{~d}$. 
a) 21 March

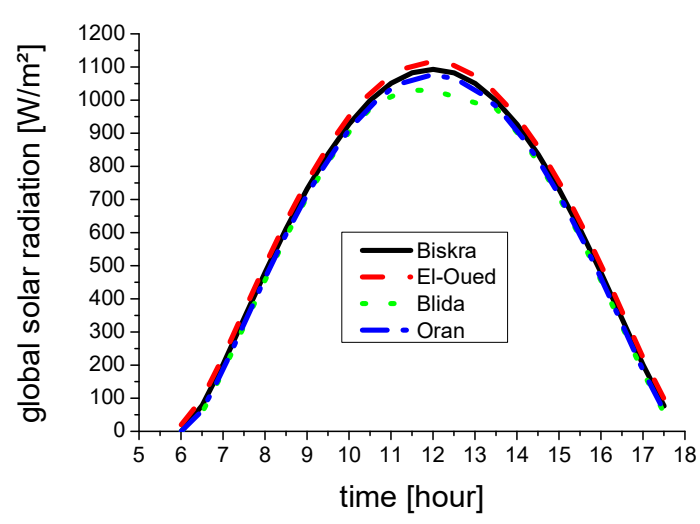

c) 21 September

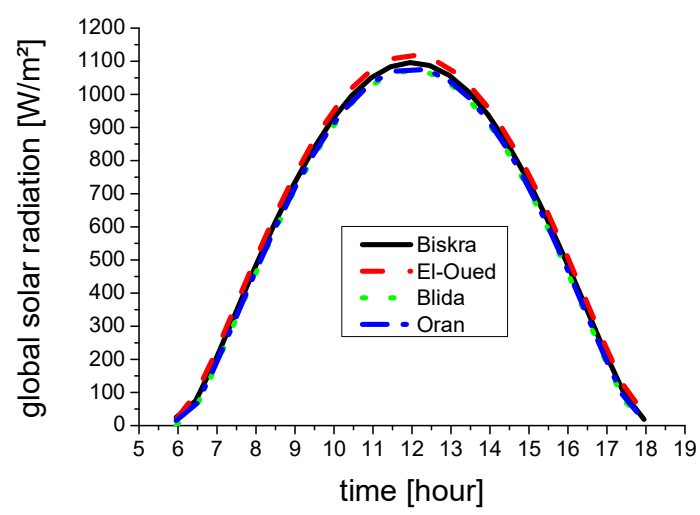

b) 21 June

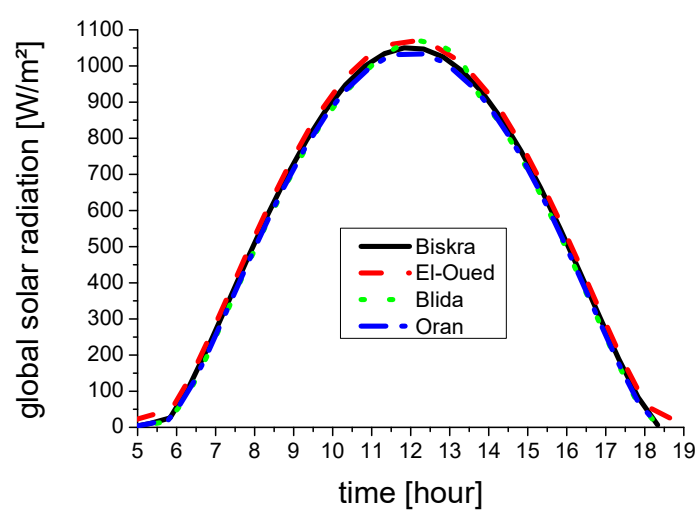

d) 21 December

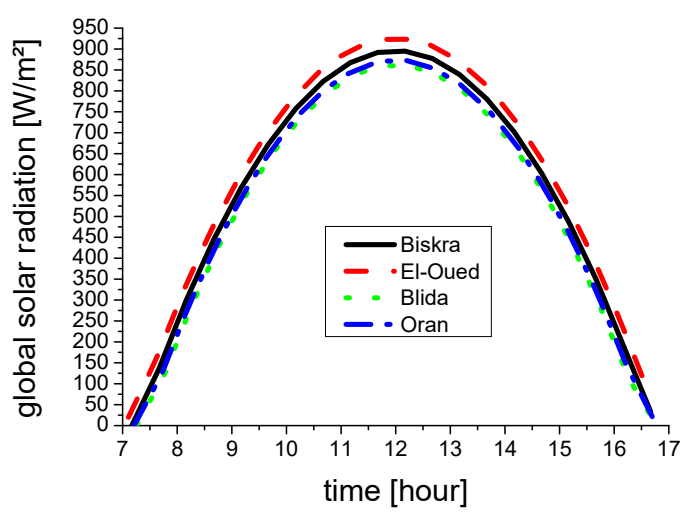

Fig.5. Evolution of global solar radiation during the four-day of the estimating.

From the curves of the figure (5), it can be said that solar radiation reaches its maximum value around noon and minimum values at sunrise and sunset. The radiation quantities received at the beginning of the day and in the last of the day are almost equivalent (the amount received at 11:00 is very similar to that received 13:00), which the vertical axis at the same point Waypoint $(x=12, y=0)$ is the symmetry axis of all the curves, this axis can be defined as follows:

$$
f(12-t)=f(12+t)=I V G S R
$$

Where, IVGSR is the Instantaneous value of the global solar radiation, and " $t$ " is a factor for definition of the time, it is changed as follows:

$$
t=1,2,3, \ldots \ldots \ldots, \frac{\Delta t}{2}
$$


$\Delta \mathrm{t}$ is the duration of the day; it can be defined as follows:

$$
\Delta t=t_{\text {sunset }}-t_{\text {sunrise }}
$$

According preventatives curves, it notes that the program can calculate and determine the daily solar radiation collected by any site on the Earth surface. The solar radiation estimation requires the knowledge to make clear many parameters, including the parameters of location (latitude, longitude and altitude) without forgetting the albedo of the place and settings that depending of the receiving surface that are:

- The inclination angle $(\beta)$ at a tilt angle equal to the latitude;

- The orientation of solar collector directed to the south.

To confirm the validity of this program, a comparison is made with results of the semi empirical model of LIU JORDAN and experimental work on the website of the University of Biskra for March 21, June 21, September 21 and December 21[22]. The figures 6a-6d illustrate the curves of comparison.

a) 21 March

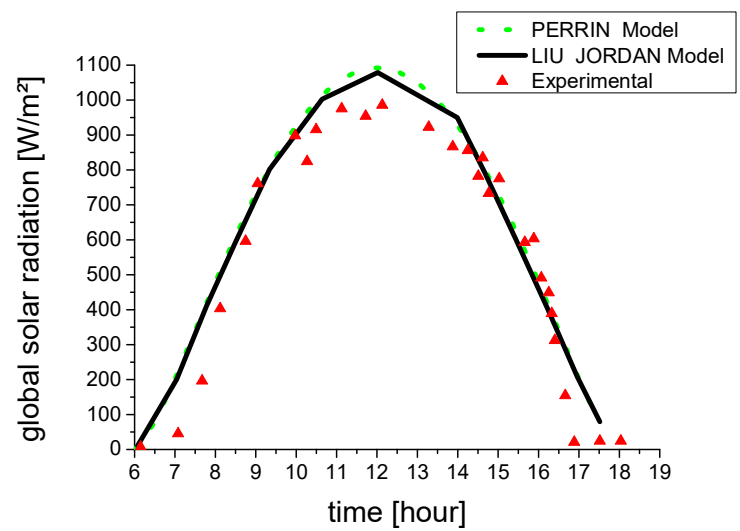

c) 21 September

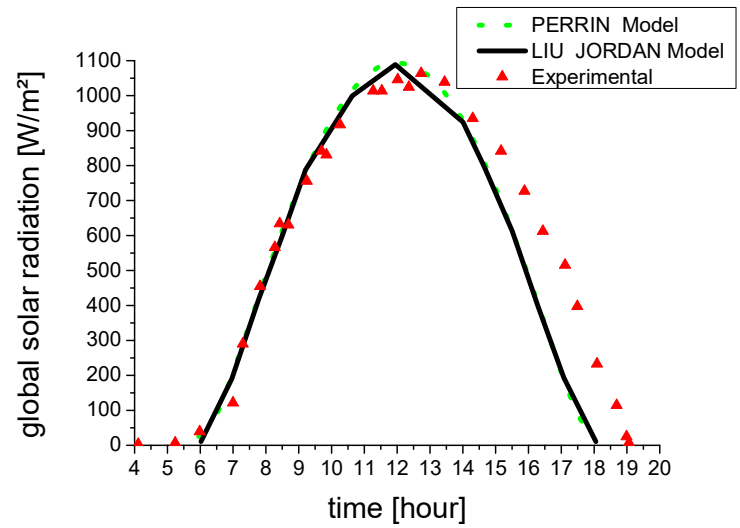

b) 21 June

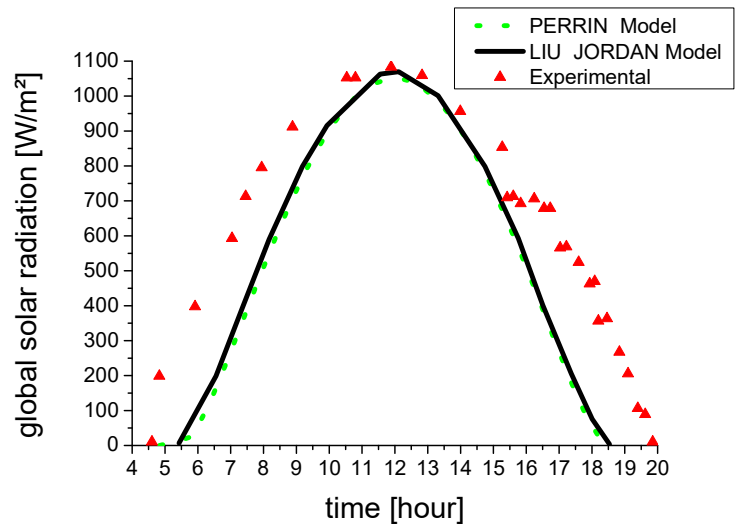

d) 21 December

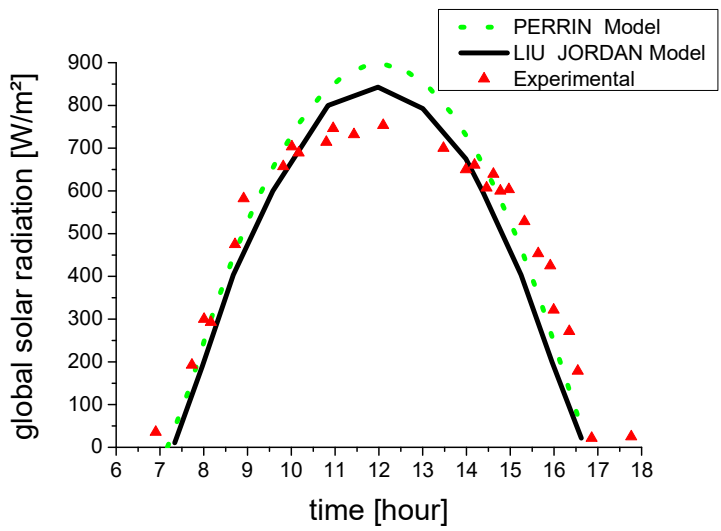

Fig.6. Comparison of results in the Biskra region.

After comparing the results of the three tools, it notices that they give very similar solar radiation values especially at noon or the difference is almost negligible. The gap that exists between the two models studied compared with experimental values is very important. Therefore, the semi empirical adjustment is conclusive and can beings considered as a solar illumination simulation model in the studied site, so in Algeria could be rely on a PERRIN DE BRICHAMBAUT model in estimating the quantity of global solar radiation, where 
Sustainable use of this potential will largely meet the demand of the heating, the air conditioning, ...etc. In previous studies, we have using this program, where we got very good results $[4,5]$.

\section{CONCLUSION}

For countries with high solar radiation such as Algeria, the application of solar renewable energy systems can make the difference and solve many problems. This study of the estimating solar radiation modeling on an inclined surface with semi-empirical model of PERRIN DE BRICHAMBAU in four sites as follows: El-Oued, Biskra, Blida and Oran. On September 21, it notes that the highest value of solar radiation recorded in El Oued and it reached $1120\left[\mathrm{~W} / \mathrm{m}^{2}\right]$ at a true solar noon and that on the day of September 21; the city of El-Oued has one of the Saharan regions with a strong luminous field; it is characterized by a hot, dry climate and a very high rate of sunshine. This program can calculate and estimate the diffuse solar radiation, direct and comprehensive anywhere on the surface of the Earth based on geographic parameters and day number of the year. This program will help researchers in the field of renewable energies in determining the amount of solar energy that can be converted into thermal energy or photovoltaic as needed.

\section{REFERENCES}

[1] wikipedia, "soleil, site web (http://fr.wikipedia.org/wiki/soleil), dernière modification le 17 mars $2015 . "$

[2] S. a. kalogirou, solar energy engineering: processes and systems, 1st ed: academic press, 2009.

[3] a. rabl, active solar collectors and their applications: newyorkoxford, oxforduniversitypress, $1985,1985$.

[4] m. ghodbane, b. boumeddane, n. moummi, s. largot, and h. berkane, "study and numerical simulation of solar system for air heating," journal of fundamental and applied sciences, vol. 8, pp. 41- 60, 2016.

[5] m. ghodbane, b. boumeddane and s. largot, "simulation numérique d'un concentrateur cylindroparabolique en el oued, algérie," international journal of scientific research \& engineering technology (ijset), vol. 3, pp. 68-74, 2015.

[6] m. ghodbane, b. boumeddane, and n. said, "design and experimental study of a solar system for heating water utilizing a linear fresnel reflector," journal of fundamental and applied sciences, vol. 8, pp. 804825, 2016.

[7] m. ghodbane, b. boumeddane, and n. said, "a linear fresnel reflector as a solar system for heating water: theoretical and experimental study," case studies in thermal engineering, vol. 8, pp. 176-186, 2016.

[8] m. ghodbane, b. boumeddane and s. largot "etude optique et thermique d'un concentrateur cylindroparabolique en site d'alger, algerie," presented at ixth international congress on renewable energy and the environment, djerba, tunisie, 18-20 march 2015.

[9] m. ghodbane, b. boumeddane, s. largot, and h. berkane, "modélisation d'un cycle de réfrigération solaire à éjecteur couplée à un concentrateur cylindro-parabolique," presented at international conférence en clean cooling technologies in the me na regions (ict3_mena'2015), bou smail, w. tipaza, 5-6 october 2015 .

[10] m. ghodbane and b. boumeddane, "a numerical analysis of the energy behavior of a parabolic trough concentrator," journal of fundamental and applied sciences, vol. 8, pp. 671-691, 2016.

[11] m. ghodbane and b. boumeddane, "numerical modeling of a parabolic trough solar collector at bouzaréah, algeria," international journal of chemical and petroleum sciences, vol. 4, pp. 11-25, 2015.

[12] vikidia, "latitude, site web (https://fr.vikidia.org/wiki/latitude), dernière modification le 20 décembre 2013."

[13] wikipedia, "el-oued,site web (http://fr.wikipedia.org/wiki/el_oued), dernière modification le 22 décembre 2014."

[14] wikipedia, "biskra, site web (http://fr.wikipedia.org/wiki/biskra), dernière modification le 17 mars 2015."

[15] wikipedia, "blida, site web (http://fr.wikipedia.org/wiki/blida), dernière modification le 16 mars $2015 . "$

[16] a. a. sfeir and g. guarracino, ingénierie des systèmes solaires - applications à l'habitat, paris ed, 1981.

[17] z. sen, "flat plate collectors," in solar energy fundamentals and modeling techniques: atmosphere, environment, climate change and renewable energy: springer, 2008, pp. 246-249.

[18] d. y. goswami and f. kreith, "solar energy resources," in energy conversion, t. f. group, ed.: crc press, 2007, pp. 5-1//5-9.

[19] j. a. duffie and w. a. b, solar engineering of thermal processes, 4th ed: wiley \& sons, inc, 2013.

[20] b. s. romdhane, "rayonnement solaire incident sur les différentes parois d'un bâtiment en tunisie en fonction de l'heure et du mois. site de web (http://solairebattunisie.voila.net/index.html)," 20/11/2006.

[21] y. jannot, thermique solaire, octobre 2003. 
[22] a. moummi, n. h. amani, n. moummi, and z. mokhtari, "estimation du rayonnement solaire par deux approches semi empiriques dans le site de biskra," presented at 8th international meeting on energetical physics, centre universitaire de béchar-algérie, 11 et 12 novembre, 2006. 